\title{
HEMICRANIA CONTINUA
}

\section{A report of ten new cases}

\author{
Marcelo E. Bigal', Stewart J Tepper ${ }^{2}$, Fred D. Sheftell ${ }^{3}$, Alan M. Rapoport ${ }^{2}$
}

\begin{abstract}
Hemicrania continua (HC) is an uncommon primary headache first described as a syndrome in 1984. Being quite unusual, its clinical characterization still demands better description. The aim of this study is to present the main clinical characteristics of 10 patients with the diagnosis of HC seen in a tertiary center, critically discussing their main features. All subjects had strictly unilateral headache without side shift and absolute response to indomethacin. Seven patients (70\%) presented autonomic features during pain exacerbations. Four (40\%) had migrainous symptoms during the exacerbations and one presented partial relief with dihydroergotamine. One patient had pain excruciatingly severe during the exacerbations. Although the cardinal features of $\mathrm{HC}$ - continuous, unilateral, indomethacin responsive, remain strongly reliable, a refinement on the clinical characterization is needful and desired.
\end{abstract}

KEY WORDS: hemicrania continua, clinical characterization, classification.

\begin{abstract}
Hemicrania continua: relato de dez novos casos
RESUMO - Hemicrania continua (HC) é uma cefaléia primária relativamente incomum primeiramente descrita enquanto sindrome em 1984. Por ser relativamente rara, sua apresentação clínica ainda carece de melhor descrição. 0 objetivo do presente estudo é apresentar e criticamente discutir as principais características clínicas de 10 pacientes com HC consecutivamente vistos em um centro de atendimento especializado. Todos os pacientes apresentavam cefaléia estritamente unilateral, sem alternância de lado e com absoluta resposta a indometacina. Sete pacientes (70\%) apresentavam sinais autonômicos durante a exacerbação da dor. Quatro (40\%) apresentavam sintomas migranosos durante as exacerbações e um apresentava alívio parcial com diidroergotamina. Um paciente apresentava exacerbações excruciantemente severas. Embora as principais características da HC - dor continua, unilateral, responsiva à indometacina - permaneçam extremamente associados à sindrome, um refinamento na caracterização clínica é necessário.
\end{abstract}

PALAVRAS-CHAVE: hemicrania continua, características clínicas, classificação.

Hemicrania continua $(\mathrm{HC})$ is an uncommon primary headache first described as a syndrome in 1984 by Sjaastad and Spierings ${ }^{1}$. They described a unilateral headache absolutely responsive to indomethacin, thus being one of the indomethacin-responsive headache syndromes ${ }^{2}$. During the next five years of its description, the number of $\mathrm{HC}$ cases reported increased to $18^{3}$. This relatively small number of cases reported in the literature at that time may have been one reason for not including $\mathrm{HC}$ in the International Headache Society (IHS) classification system ${ }^{4,5}$, this disorder being expected to be addressed in its new revision ${ }^{6}$. A clinical description of $\mathrm{HC}$ was included in the International Association for the Study of Pain classification?
Several aspects concerning its clinical characterization and consequently classification remain controversial $^{8}$. According Spierings ${ }^{2}$ and Pareja et al. ${ }^{4}, \mathrm{HC}$ is a unilateral headache syndrome with fixed lateralization, that is, the headaches always occur in the same side of the head. On the other hand, HC alternating sides, although rare, was already described ${ }^{3,9}$. Similarly, some authors consider the presence of autonomic features as a diagnostic criterion for $\mathrm{HC}^{10}$, while others consider their presence as a negative criterion ${ }^{4}$.

The aim of this study is to present the main clinical characteristics of 10 patients with the diagnosis of $\mathrm{HC}$ seen in a tertiary center, critically discussing their main features.

\footnotetext{
${ }^{1}$ M.D., Ph.D., International Headache Society Fellow; The New England Center for Headache (New York NY, USA); ${ }^{2}$ M.D., Assistant Clinical Professor of Neurology, Yale University School of Medicine; Director, The New England Center for Headache (New York NY, USA); ${ }^{3}$ M.D., Assistant Clinical Professor of Psichiatry, New York Medical College; Director, The New England Center for Headache (New York NY, USA).

Received 7 February 2002. Accepted 30 April 2002.

Dr. Marcelo E. Bigal - The New England Center for Headache - 778 Long Ridge Road, Stamford, CT - 06902 USA. E-mail: marcelobigal@hotmail.com
} 


\section{METHOD}

Clinical records and the headache diaries of 10 patients with HC seen between 1990 and 2002 at the New England Center for Headache, a tertiary referral center, were included after being randomly selected and reviewed. All patients have been followed for at least two consecutive years. During the entire time period reviewed, the clinic had utilized a uniform clinical intake form and headache calendars. The clinical intake form contains information regarding: 1 - Intensity of pain: pain is graded on a 3 point scale as severe, moderate or mild. The following parameters are evaluated for all intensities of pain the patients might present; 2 - Frequency of pain; 3 - Location of pain; 4-Quality of pain; 5- Duration of pain; 6 - Aura and associated symptoms: 7 - Behavior during attacks.

After analysis of records, spreadsheets and headache calendars, relevant information were transferred to a standardized form that included the clinical description, response to indomethacin, treatment and outcome.

\section{RESULTS}

Our sample consisted of 10 patients, being 7 (70.0\%) females, with age ranging from 34 to 61 years ( $m e a n=45.4$ years). The mean time of following was 31.3 months.

Table 1 displays the clinical characterization, response to indomethacin, response to treatment and outcome.

All subjects had strictly unilateral headache without side shift and absolute response to indomethacin. Patients 5 and 6, despite also showing an excellent response to indomethacin, developed gastric side-effects. Patient 5 did not show good outcome to other treatments, including non-steroidal anti-inflammatory, dihydroergotamine, corticosteroids and gabapentin. Patient 6 presented a satisfactory therapeutic response to rofecoxib. The 8 patients that did not have intolerance to indomethacin had complete and prolonged response.

Table 1. Clinical characterization of ten patients with hemicrania continua.

\begin{tabular}{|c|c|c|c|c|c|c|c|c|c|c|}
\hline Patients & 1 & 2 & 3 & 4 & 5 & 6 & 7 & 8 & 9 & 10 \\
\hline Unilaterality without side shift & $x$ & $x$ & $x$ & $x$ & $x$ & $x$ & $x$ & $x$ & $x$ & $x$ \\
\hline Absolute and protracted indomethacin effect & $x$ & $x$ & $x$ & $x$ & $x$ & $x$ & $x$ & $x$ & $x$ & $x$ \\
\hline Continuous but fluctuating severity & $x$ & $x$ & $x$ & $x$ & $x$ & $x$ & $x$ & $x$ & $x$ & $\mathrm{X}$ \\
\hline \multicolumn{11}{|l|}{ Intensity of pain during exacerbations } \\
\hline Mild (no exacerbations) & & & & & & $x$ & $\mathrm{x}$ & & & \\
\hline Moderate & $x$ & $x$ & & $x$ & & & & $x$ & & $x$ \\
\hline Severe & & & & & $x$ & & & & $x$ & \\
\hline Excruciatingly severe & & & $x$ & & & & & & & \\
\hline \multicolumn{11}{|l|}{ Autonomic features with severe pain exacerbations } \\
\hline a. None & $\mathrm{x}$ & & & $x$ & & $x$ & & & & \\
\hline b. Conjunctival injection & & $\mathrm{x}$ & $x$ & & & & & & $\mathrm{x}$ & $\mathrm{x}$ \\
\hline c. Lacrimation & & $x$ & & & $x$ & & & & $x$ & $x$ \\
\hline d. Nasal congestion & & $\mathrm{x}$ & & & $x$ & & & & & $\mathrm{X}$ \\
\hline e. Rhinorrhea & & & & & & & & & & $\mathrm{x}$ \\
\hline f. Ptosis & & & & & & & & & & $x$ \\
\hline g. Eyelid edema & & & & & & & $x$ & $x$ & & \\
\hline h. Idiopatic stabbing headache & & & & & & & & & $x$ & $\mathrm{x}$ \\
\hline \multicolumn{11}{|l|}{ Migraine symptoms during exacerbation } \\
\hline a. None & $x$ & $\mathrm{x}$ & $x$ & $x$ & & $x$ & $x$ & $x$ & & \\
\hline b. Throbbing pain & & & & & $x$ & & & & $x$ & $\mathrm{X}$ \\
\hline \multicolumn{11}{|l|}{ c. Nausea } \\
\hline d. Photophobia & & & & & & & & & $x$ & $x$ \\
\hline e. Phonophobia & & & & & & & & & $x$ & $x$ \\
\hline Response to antimigrainous drugs & & & & & & & & & $x$ & \\
\hline Prolonged treatment with indomethacin & $x$ & $x$ & $x$ & $x$ & & & $x$ & $x$ & $x$ & $\mathrm{X}$ \\
\hline Persistence of pain & & & & & $x$ & & & & & \\
\hline
\end{tabular}


Seven patients (70\%) presented autonomic features during pain exacerbations, as shown in Table 1. Four ( $40 \%$ ) had migrainous symptoms during the exacerbations and one presented partial relief with dihydroergotamine. One patient had pain excruciatingly severe during the exacerbations.

\section{DISCUSSION}

$\mathrm{HC}$ is an unusual, despite not rare ${ }^{8}$, primary headache. Although criteria for $\mathrm{HC}$ were not incorporated in the International Headache Society (IHS) Criteria, established in $1988^{5}$, operational criteria have been proposed ${ }^{4,10}$. Even the nosologic status of HC is not well established, with a group proposing that $\mathrm{HC}$ should be included in the group III of the IHS criteria ${ }^{4}$ and other group defending that HC must be included in the group of the chronic daily headaches $^{10}$. It seems reasonable, however, that the unique and overlapping clinical features with other trigeminal autonomic cephalalgias should assume priority over simply the number of headaches within a 30day period ${ }^{11}$.

One first mandatory feature of $\mathrm{HC}$, according the authors that first described the syndrome ${ }^{1,2}$ and one proposed diagnostic criteria ${ }^{4}$, is that the headache must be unilateral with fixed lateralization. Our 10 patients showed strictly and fixed unilateral headache. Although this seems to be by far more common, attacks that remain strictly unilateral but switch from side to side have been described in patients with $\mathrm{HC}^{12}$.

Patients with $\mathrm{HC}$ often respond in a dramatic manner to indomethacin. The complete response to indomethacin as a diagnostic test, however, remains a contentious issue, some authors arguing that this requirement is problematic ${ }^{11}$. Spierings defend that "hemicrania continua that is resistant to indomethacin, as suggested by Kuritzky ${ }^{13}$ does not exist" 2 . The IHS classification does require therapeutic response criteria to make the diagnosis of some headaches, Tolosa-Hunt syndrome being one well-know example ${ }^{5,14}$. The response to indomethacin being so dramatic, it is reasonable to consider it as a strong indicative of HC. But it seems somewhat exaggerate to consider that $\mathrm{HC}$ not responsive to indomethacin does not exist. Since this criterion does not consider the responsiveness to medications other than indomethacin, the main issue appears to relate the possibility of response to other agents. A variety of medications other than indomethacin have been repor- ted to be effective in patients with $\mathrm{HC}$, including dihydroergotamine $^{15}$, methysergide ${ }^{15}$, corticosteroids ${ }^{16}$, lamotrigine ${ }^{17}$, gabapentin ${ }^{18}$ and rofecoxib ${ }^{19}$. Our 10 patients had total and absolute response to indomethacin. With the ongoing treatment, two developed gastric side-effects. One presented good, besides not complete, response to rofecoxib.

The diagnostic criteria proposed by Pareja et al. ${ }^{4}$ require an intensity of pain from mild to severe, but not excruciatingly severe. This seems to be quite subjective. In our series, 2 (20\%) patients had mild pain without exacerbations, 5 (50\%) presented exacerbations of moderate intensity, 2 (20\%) of severe intensity, but one of our patients had exacerbations excruciatingly severe, therefore do not fulfilling this criterion. In a series of 18 patients with HC, two attempted suicide because of the severity of the headache ${ }^{3}$. A patient with a classic picture of $\mathrm{HC}$, as presented by patient number 3 , should not be excluded if her subjective experience of pain was reported as very severe ${ }^{6}$.

Although the intensity of cranial autonomic features associated with $\mathrm{HC}$ is not as intense as those seen with chronic paroxysmal hemicrania or cluster headache, and in spite of the fact that some authors consider their presence as a negative proviso ${ }^{4}$, their presence in a significant number of patients has been demonstrated ${ }^{8}$. Our data support this concept. Just $3(30 \%)$ patients did not present autonomic features during episodes of pain exacerbations.

Similarly regarding the migrainous features, also considered a negative proviso by some authors. Migraine-related symptoms are not so uncommon in $\mathrm{HC}^{6}$. Peres et al. ${ }^{8}$ reported the presence of nausea in $46 \%$ of their patients, vomiting in $15 \%$, phonophobia in $46 \%$ and photophobia in $54 \%$. The same group reported visual aura in one patient with $\mathrm{HC}^{20}$. We found migrainous features in $3(30 \%)$ patients, one presenting partial relief with dihydroergotamine.

The relative rarity of $\mathrm{HC}$ has made it difficult to figure out a comprehensive clinical picture. We aimed to present the main clinical features of this syndrome in a sample of consecutive patients seen in the tertiary care center, briefly discussing some relevant concepts. Although the cardinal features of $\mathrm{HC}$ - continuous, unilateral, indomethacin responsive, remain strongly reliable, a refinement on the clinical characterization is needful and desired. 


\section{REFERENCES}

1. Sjastaad O, Spierings EHL. "Hemicrania continua”: another headache absolutely responsive to indomethacin. Cephalalgia 1984;4:65-70.

2. Spierings EHL. The woman with continuous headache. In Rapoport AM, Sheftell FD, Purdy A (eds). Advanced therapy of headache. Hamilton: B.C. Decker; 1999:141-145.

3. Bordini C, Antonaci F, Stovner LJ, Schrader H, Sjaastad O. “Hemicrania continua": a clinical review. Headache 1991;31:20-26.

4. Pareja JA, Vincent M, Antonaci F, Sjaastad O. Hemicrania continua: diagnostic criteria and nosologic status. Cephalalgia 2001;21:874-877.

5. Headache Classification Comittee of the International Headache Society. Classification and diagnostic criteria for headache disorders, cranial neuralgias and facial pain. Cephalalgia 1988;9(Suppl 7):1-96.

6. Dodick D. Hemicrania continua: diagnostic criteria and nosologic status. Editorial Commentary. Cephalalgia 2001;21:869-872.

7. International Association for the Study of Pain Task Force on Taxonomy. Classification of chronic pain: description of chronic pain syndromes and definition of pain terms. Seattle: Seattle Press, 1994.

8. Peres MFP, Nahmias S, Silberstein SD, et al. Hemicrania continua is not that rare. Neurology 2001;57:948-951.

9. Newman LC, Lipton RB, Solomon S. Hemicrania continua: 7 new cases and literature review. Headache 1993;32:267-269.
10. Goadsby PJ, Lipton RB. A review of paroxysmal hemicranias, SUNCT syndrome and other short-lasting headaches with autonomic features, including new cases. Brain 1997;120:193-209.

11. Dodick D. Hemicrania continua: diagnostic criteria and nosologic status. Cephalalgia 2001;21:869-872.

12. Newman LC, Lipton RB, Russel M, Solomon S. Hemicrania continua: attacks may alternate sides. Headache 1992;32:237-238.

13. Kuritzky A. Indomethacin-resistant hemicrania continua. Cephalalgia 1992;12:57-59.

14. Pareja JA, Antonaci F, Vincent M. The hemicrania continua diagnosis. Cephalalgia 2001;21:940-946.

15. Young WB, Silberstein SD. Hemicrania continua and symptomatic medication overuse. Headache 1993;33:485-487.

16. Pascual J. Hemicrania continua. Neurology 1995;45:2302-2303.

17. Wheeler SD. Lamotrigine efficacy in migraine prevention. Cephalalgia 2001;21:368-373.

18. Mariano HS, Alcantra MC, Bordini CA, Speciali JG. Relief of continuous hemicrania by gabapentin: a case report. Cephalalgia 2001;21:504-509.

19. Peres MF, Zukerman E. Hemicrania continua responsive to rofecoxib. Cephalalgia 2000;20:130-131.

20. Peres MFP, Siow HC, Rozen TD. Hemicrania continua with aura. Neurology 2001;56(Suppl 3):452. 